\title{
SISTEMAS E SUCESSÕES DE CULTIVOS NA FERTILIDADE DE UM SOLO DA REGIÂOO DA AMAZÔNIA
}

\author{
Nirvani Schroeder Henrique* \\ Jairo André Schlindwein ${ }^{* *}$ \\ Elaine Cosma Fiorelli Pereira***
}

RESUMO: O manejo do solo, com técnicas que possibilitem maior sustentabilidade, visa a sustentabilidade e recuperação do solo, maiores produtividades e maior retorno econômico ao produtor. Objetivou-se com este trabalho avaliar a fertilidade do solo (fósforo, potássio, matéria orgânica e pH) em função das profundidades de amostragem e sistemas de preparo do solo e cultivo. O experimento foi instalado em um Latossolo Vermelho-Amarelo. Foi utilizado um esquema de parcela subsubdividida. Os preparos de solo foram: 1 - PRT - preparo tradicional (uma grade aradora e duas grades niveladoras), 2 - PRA - preparo alternativo (subsolagem), 3 - PDA plantio direto com um preparo alternativo a cada quatro anos e 4 - PDC - plantio direto contínuo. O segundo fator utilizado foi a sequência de culturas, sendo estas: 1) SF: soja - feijão; 2) MF: milho - feijão; 3) SM: soja - milho; 4) MM: milho - milho. O PRT e PDC apresentaram menor fertilidade e na camada superficial do solo. O PRT apresentou menores quantidades de fósforo, potássio e matéria orgânica e o pH foi menor no PDC e no PRT.

PALAVRAS-CHAVE: Atributos químicos; Manejo do solo; Sucessão de culturas.

\section{CULTURE SYSTEMS AND SUCCESSIONS IN SOIL FERTILITY IN THE AMAZON REGION}

ABSTRACT: Soil management, featuring techniques that make possible great sustainability, aims at soil recuperation and sustainability, greater productivity and greater economic gain to the producer. Soil fertility (phosphorus, potassium, organic matter, $\mathrm{pH}$ ) is evaluated with regard to depth of samples and soil and crop preparation

Engenheira Agrônoma. Mestrado em Ciências ambientais pelo Programa de Pós-Graduação em Ciências Ambientais. Docente do Ensino básico, técnico e tecnológico do Instituto Federal de Educação, Ciência e Tecnologia de Rondônia, Brasil. E-mail: nirvani.henrique@ifro.edu.br

** Engenheiro Agrônomo. Doutorado em Ciência do Solo pela Universidade Federal do Rio Grande do Sul. Docente Adjunto da Universidade Federal de Rondônia, Brasil.

*** Engenheira Agrônoma. Doutorado em Desenvolvimento Regional e Meio Ambiente pela Fundação Universidade Federal de Rondônia. Docente da Universidade Federal de Rondônia, Brasil. 
systems. Experiment was undertaken in Red-Yellow Latisol and a sub-subdivided split scheme was adopted. Soil preparations comprised (1) PRT - traditional preparation (plowing grid and two level grids); (2) PRA - alternative preparation (subsoil); (3) PDA - zero tillage with alternative preparation every four years; (4) PDC continuous zero tillage. Crop sequence was the second factor employed, namely: (1) SF: soybean - beans; (2) MF: corn - bean; (3) SM: soybean - corn; 4) MM: corn - corn. PRT and PDC presented lower fertility rate at the soil surface layer. PRT presented less amounts of phosphorus, potassium and organic matter; $\mathrm{pH}$ had lower rates in PDC and PRT.

KEY WORDS: Chemical attributes; Soil management; Culture succession.

\section{INTRODUÇÃO}

Os tipos de manejo do solo, quando realizados de forma inadequada, podem favorecer a degradação do solo (MACEDO, 2009), interferindo negativamente nos atributos físicos, químicos e biológicos do solo.

No sistema de preparo tradicional, o uso excessivo de máquinas pesadas para o preparo do solo pode causar modificações na sua estrutura, resultando em maior desagregação de partículas na camada mobilizada e compactação abaixo dessa camada, interferindo na infiltração de água e no desenvolvimento radicular das culturas. Além disso, há redução do acúmulo de resíduos culturais quando o solo é revolvido intensivamente, pois com o revolvimento há maior contato dos resíduos com o solo e a decomposição é mais rápida e consequentemente há maior perda de carbono para a atmosfera (BARRETO et al., 2008).

Com menor cobertura vegetal sobre a superfície do solo há maior aquecimento, maior perda de umidade (MARTORANO et al., 2009) e maior exposição ao impacto direto das gotas de chuvas facilitando a erosão laminar do solo, que, por sua vez, em geral, é a mais fértil (MOLINE et al., 2009) e, em consequência, há redução da fertilidade desses solos.

Atualmente, o plantio direto é a tecnologia agrícola disponível que mais se aproxima das condições em que a natureza opera, pois evita a mobilização do solo, mantendo a superfície protegida por resíduo, além de ser aplicável a praticamente 
todas as culturas comerciais, inclusive na cana-de-açúcar e cultura perene. O plantio direto integra a geração de lucro e a proteção do ambiente, inserindo a sustentabilidade nos processos produtivos (ALMEIDA JÚNIOR et al., 2010; DRUGOWICH et al., 2014).

O uso de rotação de cultura no plantio direto e ausência de revolvimento promovem o acúmulo de palhada sobre a superfície do solo. O solo sob a palhada de cobertura permanece com temperatura menor nas horas quentes do dia quando comparado ao solo descoberto e, além disso, mantém-se mais úmido, especialmente na camada superficial, este efeito possivelmente é devido à maior infiltração de água no solo e menor evaporação. Tão importante quanto à infiltração de água é a proteção do solo contra os impactos das gotas de chuva, evitando, assim, o processo erosivo (PRIMAVESI, 2010).

Perez et al. (2009) afirmam que os resíduos culturais propiciam outros benefícios ao solo como a ciclagem de nutrientes, aumento dos teores de matéria orgânica do solo e redução da temperatura do solo na camada superficial refletindo em maior eficiência de absorção de água e nutrientes pelas plantas e consequentemente maior produtividade. No entanto, Almeida et al. (2008) não verificaram efeito das plantas de cobertura guandu, crotalária, mucuna-preta, milheto e do pousio sobre o $\mathrm{pH}$, a acidez potencial e o teor de matéria orgânica em área de preparo convencional e plantio direto com 3 anos de implantação. Favorato et al. (2015) encontraram comportamento semelhante nos atributos químicos de solos manejados tanto no plantio direto como no convencional, ambos cultivados com aveia preta e tremoço branco como plantas de cobertura.

Manejos conservacionistas, como o plantio direto, favorecem a decomposição mais lenta da matéria orgânica do solo e contribuem para o acúmulo de maior quantidade de carbono no solo quando comparado ao convencional, e, desta forma, desaceleram as perdas de carbono para atmosfera (FERREIRA et al., 2010). Além disso, as propriedades biológicas são melhoradas (LOPES et al., 2012), pois possuem maior carbono disponível para os micro-organismos e, consequentemente, as plantas se beneficiam pelas propriedades melhoradas (ANGHINONI, 2007).

Apesar dos vários benefícios proporcionados pelo plantio direto, Gozubuyuk et al. (2014) abordam que nesse sistema ocorre resistência à penetração das 
raízes das plantas e redução da macroporosidade devido ao intenso tráfego de máquinas para operações como plantio, colheita, adubação de cobertura e pulverizações de defensivos para o controle de pragas e doenças em condição de solo úmido, que pode resultar em menores produtividades.

Objetivou-se com este trabalho avaliar a fertilidade do solo ( $\mathrm{pH}, \mathrm{P}, \mathrm{K}$ e MOS) em diferentes profundidades de amostragem de um solo cultivado em diferentes sistemas de preparo do solo e plantio.

\section{MATERIAL E MÉTODOS}

O experimento foi instalado em novembro de 2007, porém os dados utilizados para a presente pesquisa foram obtidos no quarto ano de cultivo (2011-12). A área está localizada no Campus Experimental da Fundação Universidade Federal de Rondônia - UNIR, localizado no município de Rolim de Moura (RO). O clima é tropical quente e úmido. As quantidades de chuvas variam entre 1400 a $2600 \mathrm{~mm}$ por ano, e os meses que apresentam chuvas mais intensas são de outubro a abril. Os meses entre julho e agosto apresentam menos de $50 \mathrm{~mm}$ de chuva por mês; a temperatura do ar na média varia entre $24 \mathrm{e} 26^{\circ} \mathrm{C}$; a umidade relativa do ar varia em torno de $75 \%$ no outono e inverno e de $80 \%$ a 90\% no verão (RONDÔNIA, 2012).

A área experimental está instalada em um Latossolo Vermelho-Amarelo com $2 \%$ de declividade. Anteriormente à instalação, a área era ocupada por capoeira e após a instalação as parcelas foram cultivadas, sem irrigação, com as espécies milho, soja e feijão, conforme as respectivas sucessões definidas para cada unidade experimental.

O delineamento é em blocos casualisados com esquema de parcelas subsubdivididas. Foram analisados 4 preparos do solo (fator principal) com 4 rotações de culturas (fator secundário) e 3 repetições, totalizando 12 parcelas e 48 sub-parcelas, sendo cada sub-parcela de 59,4 $\mathrm{m}^{2}$ cada, resultando uma área total de 2851,2 $\mathrm{m}^{2}$. Cada parcela foi amostrada em 3 profundidades.

O fator métodos de preparo e plantio do solo representa diferentes níveis de mobilização: 1 - PRT - preparo tradicional (uma operação com grade aradora e uma 
com grade niveladora), 2 - PRA - preparo alternativo (uma operação de subsolagem com $40 \mathrm{~cm}$ de profundidade), 3 - PDA - plantio direto com um preparo alternativo a cada quatro anos e 4 - PDC - plantio direto contínuo. O fator sequência de culturas, cultivadas de outubro a fevereiro e de fevereiro a maio são: 1) SF: soja - feijão; 2) MF: milho - feijão; 3) SM: soja - milho; 4) MM: milho - milho. As profundiades de solo analisadas foram 0-10, 10-20 e 20-30 cm.

Após o preparo do solo, conforme os tratamentos, foi realizada a adubação de plantio das culturas de safra (RIBEIRO; GUIMARÃES; ALVAREZ, 1999), no entanto, a soja não recebeu adubação nitrogenada pois as sementes foram inoculadas antes do plantio e, em novembro de 2010, foi realizado o plantio das culturas do primeiro ciclo. A calagem só foi realizada na instalação do experimento.

As espécies utilizadas para o primeiro plantio (safra) foram a soja valiosa RR e o milho AL Bandeirante, com 13 e 4,65 plantas por metro linear respectivamente e ambas com espaçamento entrelinhas de $65 \mathrm{~cm}$. O plantio das culturas de safrinha (milho e feijão) foi feito no mês de fevereiro com espaçamento entre linhas de $65 \mathrm{~cm}$ e espaçamento entre plantas de 4,65 e 15 plantas por metro linear, respectivamente.

$\mathrm{Na}$ adubação do milho, no primeiro e no segundo plantio, foram adicionados ao solo $80 \mathrm{~kg} \mathrm{ha}^{-1}$ de $\mathrm{P}_{2} \mathrm{O}_{5}$ no plantio, $60 \mathrm{~kg} \mathrm{ha}^{-1}$ de $\mathrm{K}_{2} \mathrm{O}$ no plantio, $20 \mathrm{~kg} \mathrm{ha}^{-1} \mathrm{de}$ $\mathrm{N}$ no plantio e $100 \mathrm{~kg} \mathrm{ha}^{-1}$ de $\mathrm{N}$ em duas aplicações de cobertura, com 6 e 10 folhas. Para a cultura da soja foram adicionados $80 \mathrm{~kg} \mathrm{ha}^{-1} \mathrm{de}_{2} \mathrm{O}_{5}$ e $80 \mathrm{~kg} \mathrm{ha}^{-1}$ de $\mathrm{K}_{2} \mathrm{O}$ ambos no plantio e para a cultura do feijão foram fornecidos $60 \mathrm{~kg} \mathrm{ha}^{-1}$ de $\mathrm{P}_{2} \mathrm{O}_{5}$ no plantio, $20 \mathrm{~kg} \mathrm{ha}^{-1}$ de $\mathrm{K}_{2} \mathrm{O}$ no plantio, $20 \mathrm{~kg} \mathrm{ha}^{-1}$ de $\mathrm{N}$ no plantio e $30 \mathrm{~kg} \mathrm{ha}^{-1}$ de $\mathrm{N}$ em cobertura, com 25 dias após a emergência das plantas.

Todos os tratos de culturas como controle de plantas invasoras, insetos e doenças foram realizados conforme a necessidade e recomendação para cada cultura de safra ou safrinha e após a colheita os restos culturais foram devolvidos nas parcelas de forma manual.

Para a determinação da fertilidade do solo, foram coletadas três subamostras em cada parcela para formação de uma amostra composta, sendo retiradas nas profundidades de 0-10, 10-20 e 20-30 cm. As amostras foram retiradas com pá de corte e a profundidade de amostragem aferida com régua graduada de $30 \mathrm{~cm}$. Após coletadas, as amostras foram secas por 48 horas a $105{ }^{\circ} \mathrm{C}$ e tamizadas em peneira 
de $2 \mathrm{~mm}$ e posteriormente submetidas à análise química. Para as variáveis de $\mathrm{P}, \mathrm{K}$, MO e pH em água foram utilizadas as metodologias descritas por Tedesco, Gianello e Biasani (1995).

Os dados obtidos foram submetidos a análises de variância ao nível de 5\% de probabilidade, utilizando o Teste de Tukey.

\section{RESULTADOS E DISCUSSÃO}

Para todos os atributos analisados (MO, potássio, fósforo e $\mathrm{pH}$ ) não houve interação significativa com o fator sucessão de culturas, possivelmente devido ao pouco tempo de implantação dos sistemas. No entanto, é recomendado alternar espécies com sistemas radiculares diferentes, uma com maior capacidade de absorção de nutrientes e outra com menor exigência em nutriente. Além de ser recomendada a utilização de espécies que exploram o solo em diferentes profundidades (LEPSCH, 2010). A sucessão de culturas, dentre outros fatores, melhora as condições físicas do solo, quebra o ciclo de insetos pragas e patógenos que têm preferência por determinadas culturas (SALOMÃO, 2007) e proporciona a adição de resíduos vegetais (LEPSCH, 2010).

Os teores de matéria orgânica (MO) apresentaram interação apenas entre preparo de solo com as profundidades de amostragem de solo, sendo observado um decréscimo no teor de MO nas camadas mais profundas do solo no PDA, PDC e PRA (Gráfico 1). Não houve revolvimento do solo no PDA e PDC, devido a isso há um acúmulo de palhada na superfície do solo proveniente das culturas em sucessão, que ao entrar em decomposição resultam em matéria orgânica. Para PRA o resultado pode ser atribuído à operação de subsolagem que promove apenas a descompactação e não inverte o perfil do solo promovendo a incorporação da MO no perfil e, assim, sua distribuição. Seki et al. (2015) avaliaram a influência da subsolagem e da escarificação sobre a manutenção da cobertura do solo e concluíram que os dois tipos de manejo do solo influenciaram a manutenção de cobertura, assim como a densidade e o conteúdo de água no solo, porém não interferiram no desenvolvimento das plantas e na produtividade de grãos, na cultura do milho. 
O PDC apresentou teores de MO menores quando comparado ao PDA o que não era esperado já que os sistemas de preparo de solo são semelhantes e o sistema de plantio direto tem como uma das principais vantagens a manutenção da matéria orgânica no solo em função da deposição da palhada (ROSCOE; MERCANTE; SALTON, 2006) como descrito por Lima, Oliveira e Silva (2012), que encontraram aumento de matéria orgânica e maior concentração de nutrientes em solo com maior resíduo de planta de cobertura, afirmando a contribuição da palhada para a presença de MO no solo.

\section{Matéria orgânica}

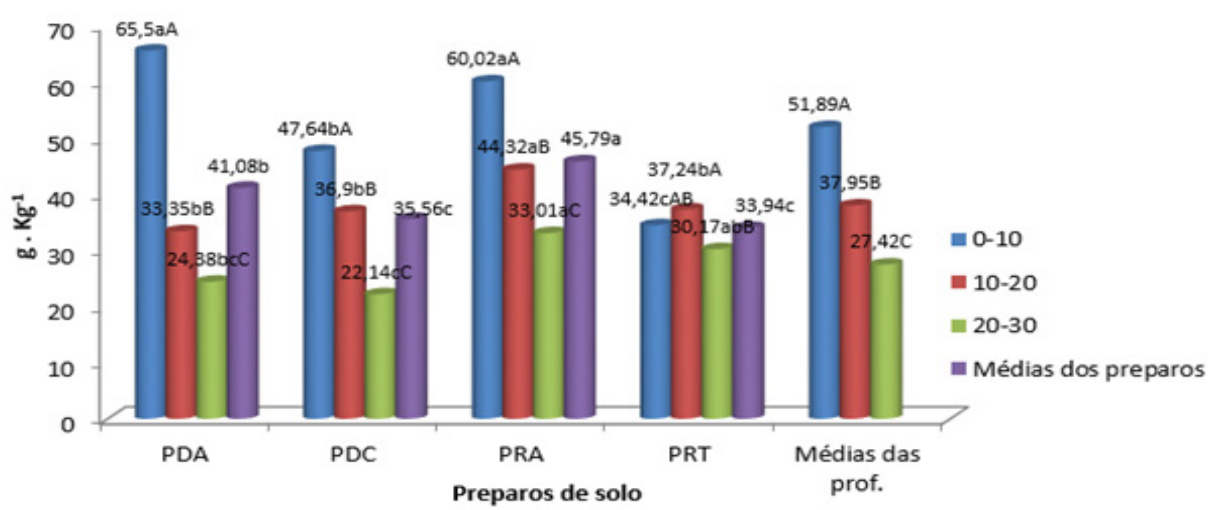

Médias seguidas da mesma letra, minúscula nos preparos de solo e maiúsculas nas profundidades, não diferem entre si pelo Teste de Tukey a 5\% de probabilidade

Gráfico 1. Teores de matéria orgânica em solo com Plantio Direto Alternativo (PDA), Plantio Direto Convencional (PDC), Preparo Alternativo (PRA) e Preparo Tradicional (PRT) em diferentes profundidades.

$\mathrm{Na}$ análise estatística para os teores de potássio (K) houve interação apenas entre preparo do solo e profundidade de amostragem.

O PDC e o PDA apresentaram maior presença de potássio na camada de 0-10 cm, pois são preparos do solo sem revolvimento os quais favorecem o aumento deste nutriente na camada superficial do solo. O acúmulo de potássio na camada de 0-10 cm também é favorecido pela adubação potássica em superfície, pela ciclagem de nutrientes e a rápida mineralização do potássio na decomposição da biomassa. 
Leite (2010), estudando a influência do plantio direto com diferentes tempos de implantação e o cultivo convencional, encontrou maior presença de $\mathrm{K}$ na superfície do solo nos preparos sem revolvimento e redução dos teores de potássio à medida que também diminui os teores de matéria orgânica.

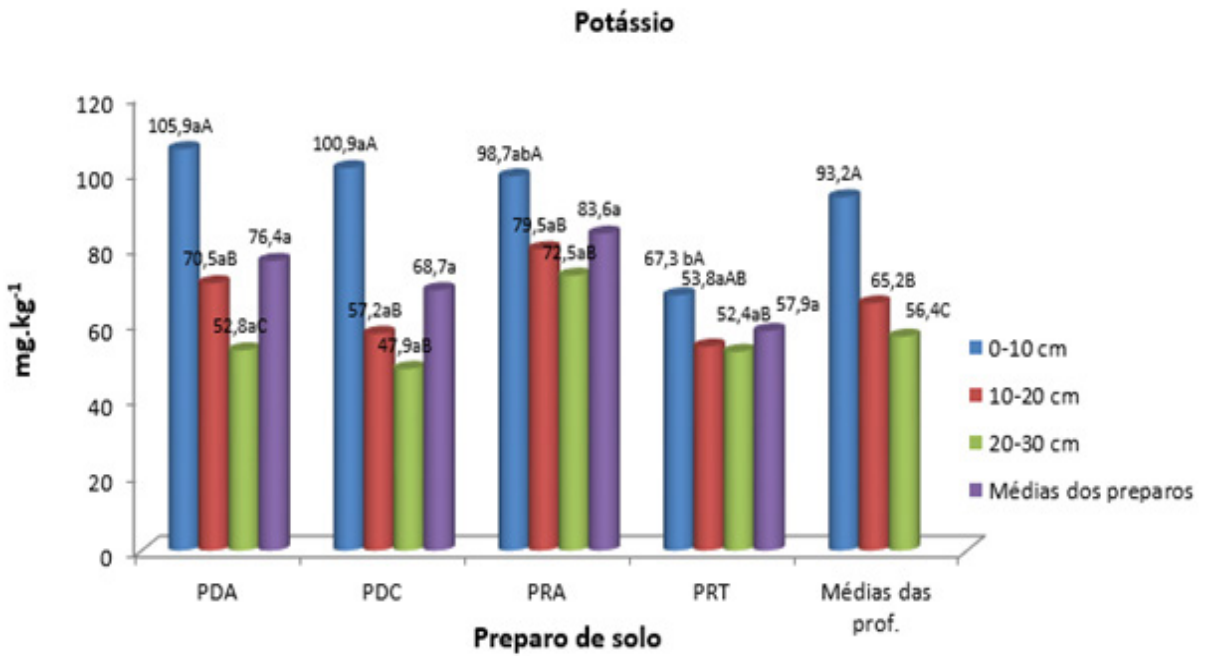

Médias seguidas da mesma letra, minúscula nos preparos de solo e maiúsculas nas profundidades, não diferem entre si pelo Teste de Tukey a 5\% de probabilidade.

Gráfico 2. Teores de potássio em solo com Plantio Direto Alternativo (PDA), Plantio Direto Convencional (PDC), Preparo Alternativo (PRA) e Preparo Tradicional (PRT) em diferentes profundidades.

O PRT apresentou maior quantidade de potássio na profundidade de 10-20 $\mathrm{cm}$ provavelmente devido ao revolvimento do perfil do solo até os 20 centímetros no momento do preparo. No entanto, no PRA foi verificada maior quantidade de potássio na profundidade de $20-30 \mathrm{~cm}$, pois a subsolagem que promove a descompactação e proporciona maior infiltração de água no perfil do solo pode ter facilitado a descida deste nutriente, já que este tem boa mobilidade vertical no perfil do solo e é facilmente lixiviado no solo com efeito da água da chuva, pois é um nutriente que, em grande parte, integra a fração orgânica viva e é lavado do material orgânico logo após a morte das células (ERNANI; ALMEIDA; SANTOS, 2007).

De maneira geral, as interações dos teores de potássio decrescem com a profundidade de amostragem em todos os preparos de solo e os maiores teores de potássio foram encontrados nas interações PDA - 0-10 e PDC - 0-10. 
Cavalcante et al. (2007) encontraram no sistema de plantio direto um acúmulo significativo de matéria orgânica, fósforo, potássio e elevação da CTC quando comparado com solo sob vegetação natural, pastagem e plantio convencional, além da melhoria nas condições químicas do solo.

Os teores de fósforo não apresentaram interação entre os fatores analisados e não apresentaram diferença entre as médias dos fatores de preparo do solo e sucessão de culturas, sendo que apenas apresentaram diferença nas médias das profundidades de solo (Gráfico 3), onde a camada de 0-10 cm mostrou maior presença de fósforo seguido das profundidades de 10-20 e 20-30 centímetros, conforme pode ser observado no Gráfico 3.

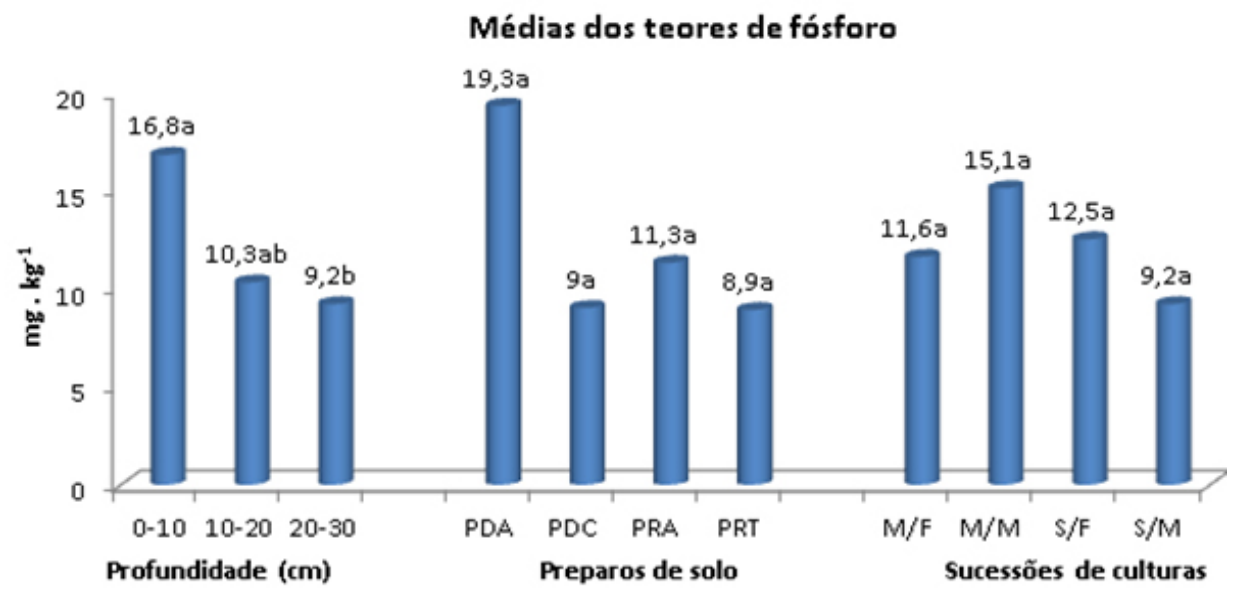

PDA: Plantio direto alternativo; PDC: Plantio direto convencional; PRA: Preparo alternativo; PRT: Preparotradicional; M/F: milho/feijão; M/M: milho/milho; S/F: soja/feijão e S/M: soja/milho.

Gráfico 3. Médias dos teores de fósforo em diferentes profundidades, preparos de solo e sucessões de culturas de um Latossolo Vermelho Amarelo submetido a diferentes tratamentos.

É esperado que na superfície do solo seja encontrado maior acúmulo de fósforo, pois este é muito reativo e pouco móvel no solo e não se perde facilmente com a lixiviação no perfil do solo, sendo a concentração superficial favorecida pela adubação em superfície e ciclagem de nutrientes. Resultados semelhantes também foram encontrados por Cavalcante et al. (2007), onde observaram maior acúmulo de fósforo na superfície do solo, bem como a diminuição dos teores em profundidade para todos os sistemas de preparo de solo estudados. 
Os resultados dos teores de fósforo nas sucessões de culturas não mostraram coerência devido, possivelmente, ao pouco tempo de sucessão para que ocorram alterações significativas dos teores de fósforo no solo, no entanto, é esperado maior presença de fósforo em solo cultivado com plantas leguminosas devido à presença de maiores concentrações do nutriente nas leguminosas e pela rápida mineralização e decomposição comparado com as gramíneas que possuem maior relação C/N (SANTOS et al., 2012), pois quanto menor a relação C/N dos resíduos culturais maior é a taxa de decomposição (CRUSCIOL et al., 2008).

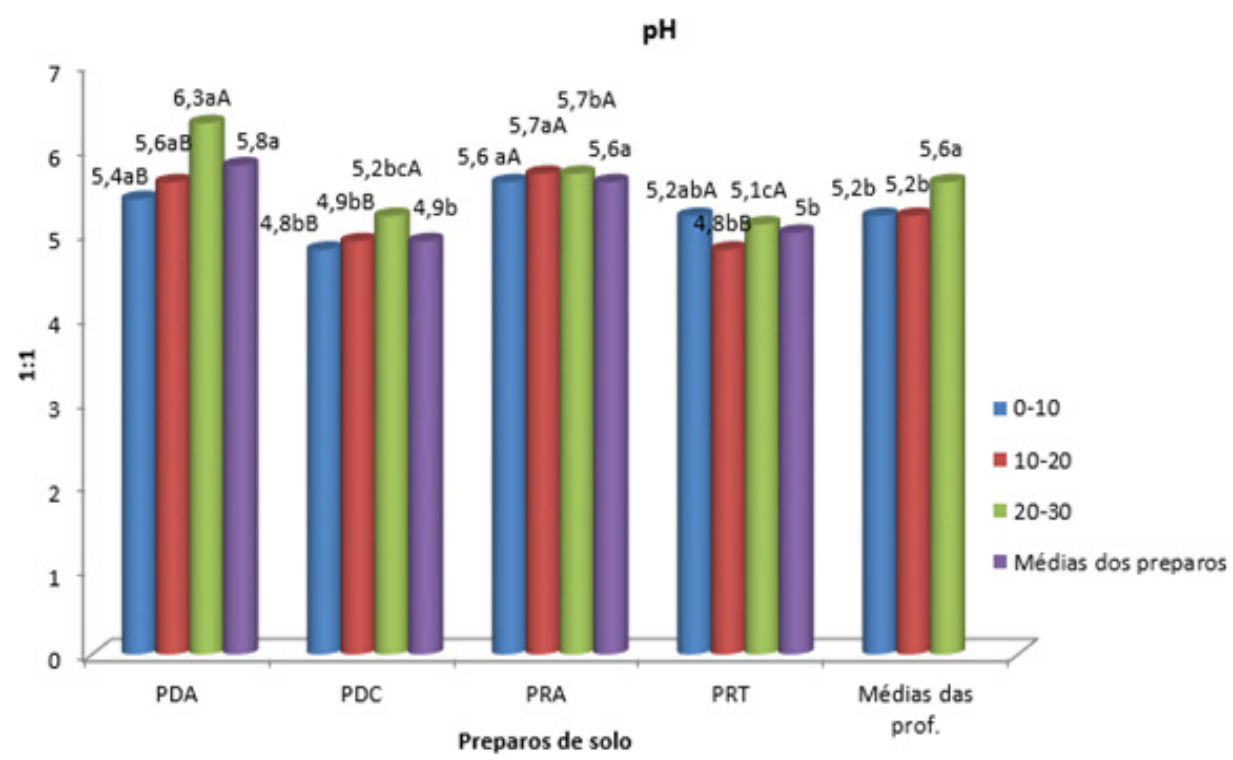

Médias seguidas da mesma letra, minúscula nos preparos de solo e maiúsculas nas profundidades, não diferem entre si pelo Teste de Tukey a 5\% de probabilidade.

Gráfico 4. pH do solo manejado com Plantio Direto Alternativo (PDA), Plantio Direto Convencional (PDC), Preparo Alternativo (PRA) e Preparo Tradicional (PRT) em diferentes profundidades.

A acidez do solo, medido em potencial hidrogeniônico $(\mathrm{pH})$ apresentou interação apenas entre preparo de solo e profundidade de amostragem, conforme observado no Gráfico 4.

No PRT há menor pH na profundidade de $10-20 \mathrm{~cm}$ quando comparado à profundidade de $0-10 \mathrm{~cm}$ (Gráfico 4) devido à inversão do perfil do solo com arado até os $20 \mathrm{~cm}$ de profundidade. 
Quando analisadas as interações, observa-se que o valor de $\mathrm{pH}$ é menor na profundidade de 0-10 cm no PDA e PDC. É comum encontrar, em sistema de plantio direto, menor $\mathrm{pH}$ em camadas mais profundas devido à realização de calagem em superfície, porém a área em estudo só recebeu calagem há 4 anos na instalação dos sistemas de preparo, seguidos de incorporação do calcário. No entanto, é esperado que ocorra um processo de acidificação natural na superfície do solo, isso se deve a alguns fatores como a de perdas de cátions básicos que são absorvidos pelas plantas, acidificação da matéria orgânica, ação de agentes de intemperismo como o clima e os organismos, maior efeito da adubação nitrogenada, é a zona de desenvolvimento radicular e migração dos elementos minerais, principalmente o cálcio (ANGHINONI, 2007; SOUSA; MIRANDA; OLIVEIRA, 2007).

\section{CONSIDERAÇÕES FINAIS}

Houve maior acúmulo de fósforo, potássio e matéria orgânica e menor $\mathrm{pH}$ na superfície do solo em sistemas de preparo de solo sem revolvimento.

As sucessões de culturas não influenciaram no aumento da fertilidade do solo em função do pouco tempo de cultivo das espécies.

No PRT e no PDC, apesar de não ser um resultado esperado neste último, houve menores teores de fósforo e potássio quando comparado ao PDA e PRA, sendo necessária a adubação com doses diferentes de fertilizantes em cada preparo de solo para ambos alcançarem o mesmo nível de fertilidade.

\section{REFERÊNCIAS}

ALMEIDA JÚNIOR, A. R. de. Boas práticas agropecuárias. São Paulo, v. 01, p. 20-22. 2010. Disponível em: <http://cms20.happybiz.com.br/Arquivos/ Empresa_020CONTEUDO_00000033_Anexos/Original/020000000330016_0.pdf > . Acesso em: 25 jul. 2017

ALMEIDA, V. P.; ALVES, M. C.; SILVA, E. C.; OLIVEIRA, S. A. Rotação de culturas e propriedades físicas e químicas em Latossolo Vermelho de cerrado sob preparo convencional e semeadura direta em adoção. Revista Brasileira de Ciências do Solo, v. 32, p. 1227-1237, 2008. 
ANGHINONI, I. Fertilidade do solo e seu manejo em sistema plantio direto. In: NOVAIS, F. R.; ALVARES, V. V. H.; BARROS, N. F.; FONTES, R. L.; CANTARUTTI, R. B.; NEVES, J. C. L. (Ed.). Fertilidade do solo. Viçosa, 2007, p. 878-880.

BARRETO, A. C.; FREIRE, M. B. G. S.; NACIF, P. G. S.; ARAÚJO, Q. R.; FREIRE, F. J.; INÁCIO, E. S. B. Fracionamento químico e físico do carbono orgânico total em um solo de mata submetido a diferentes usos. Revista Brasileira de Ciência do Solo, Viçosa, v. 32, n. 1, p. 1471-1478, 2008.

CAVAlCANTE, E. G. S.; ALVES, M. C.; PEREIRA, G. T.; SOUZA, Z. M. Variabilidade espacial de MO, P, K e CTC do solo sob diferentes usos e manejos. Ciência Rural, Santa Maria, v. 37, n. 2, p. 394-400, 2007.

CRUSCIOL, C. A. C.; MORO, E.; EDUARDO DO VALLE LIMA, E. V.; ANDREOTTI, M. Taxas de decomposição e de liberação de macronutrientes da palhada de aveia preta em plantio direto. Bragantia, Campinas, v. 67, n. 2, p. 481-489, 2008.

DRUGOWICH, M. I. et al. Boas práticas em conservação do solo e da água. Campinas: Imprensa Oficial do Estado de São Paulo, 2014. 40 p. (Manual Técnico - CATI, n 81).

ERNANI, P. R.; ALMEIDA, J. A.; SANTOS, F. C. Potássio. In: NOVAIS, F. R.; ALVARES, V. V. H.; BARROS, N. F.; FONTES, R. L.; CANTARUTTI, R. B.; NEVES, J. C. L. (Ed.). Fertilidade do solo. Viçosa, 2007, p. 551-570.

FAVARATO, L. F.; SOUZA, J. L.; GALVÃO, J. C. C.; SOUZA, C. M.; GUARÇONI, R. C. Atributos químicos do solo com diferentes plantas de cobertura em sistema de plantio direto orgânico. Revista Brasileira de Agropecuária Sustentável, Viçosa, v. 5, n. 2, p. 19-28, Dezembro, 2015.

FERREIRA, E. P. B.; SANTOS, H. P.; COSTA, J. R.; DE-POLLI, H.; RUMJANEK, N. G. Microbial soil quality indicators under different crop rotations and tillage management. Revista Ciência Agronômica, Fortaleza, v. 41, n. 2, p. 177-183, June 2010.

GOZUBUYUK, Z. et al. Tillage effects on certain physical and hydraulic properties of a loamy soil under a crop rotation in a semiarid region with a cool climate. Catena, v. 118, p. 195-205, 2014. 
LEITE, L. F. C. Atributos químicos e estoque de carbono em Latossolo sob plantio direto no Cerrado do Piauí. Revista Brasileira de Engenharia Agrícola e Ambiental, Campina Grande, v. 14, n. 12, p. 1273-1280, 2010.

LEPSCH, I. F. Formação e conservação dos solos. 2. ed. São Paulo: Oficina de Textos, 2010. $216 \mathrm{p}$.

LIMA, J. S. S.; OLIVEIRA, R. B.; SILVA, S. A. Spatial variability of particle size fractions of an Oxisol cultivated with conilon coffee. Revista Ceres, Viçosa, v. 59, n. 6, p. 867 872, dec. 2012.

LOPES, H. S. S.; MEDEIROS, M. G.; SILVA, J. R.; MEDEIROS JÚNIOR, F. A.; SANTOS, M. N.; BATISTA, R. O. Biomassa microbiana e matéria orgânica em solo de Caatinga, cultivado com melão na Chapada do Apodi, Ceará. Revista Ceres, Viçosa, v. 59, p. 565-570, 2012.

MACEDO, M. C. M. Integração lavoura e pecuária: o estado da arte e inovações tecnológicas. Revista Brasileira de Zootecnia, Brasília, 38, p. 133-146, 2009.

MARTORANO, L. G.; BERGAMASCHI, H.; DALMAGO, G. A.; FARIA, R. T.; MIELNICZUK, J.; COMIRAN, F. Indicadores da condição hídrica do solo com soja em plantio direto e preparo convencional. Revista Brasileira de Engenharia Agrícola e Ambiental, Campina Grande, v. 13, n. 4, p. 397-405, 2009.

MOLINE, E. F. V.; FARIAS, E. A. P.; ZIBETTI, J. L.; BRASILINO, M. F.; LIMA, P. P.; SCHLINDWEIN, J. A. Perdas de água e solo em solo com diferentes quantidades de cobertura submetido à chuva artificial na Zona da Mata de Rondônia. In: CONGRESSO BRASILEIRO DE CIÊNCIA DO SOLO, 32, 2009, Fortaleza. Anais... Fortaleza: SBCS, 2009.

PEREZ, A. A. G.; SORATTO, R. P.; MANZATTO, N. P. Nitrogênio na semeadura e em cobertura para o feijoeiro em sistema plantio direto recém-implantado e consolidado. In: Congresso Brasileiro de Ciência do Solo, 32, 2009, Fortaleza. Anais... Fortaleza: SBCS, 2009. 
PRIMAVESI, A. Manejo ecológico do solo: a agricultura em regiões tropicais. São Paulo: Nobel, 2010.

RONDÔNIA. Secretaria Estadual de Desenvolvimento Ambiental. Meteorologia: Boletins climatológicos anuais 2012. Disponível em: < http://www.sedam.ro.gov.br > . Acesso em: 10 jun. 2016.

RIBEIRO, A. C.; GUIMARÃES, P. T. G.; ALVAREZ, V. V. H. (Ed.). Recomendações para o uso de corretivos e fertilizantes em Minas Gerais: $5^{\circ}$ Aproximação. Viçosa: Comissão de Fertilidade do Solo do Estado de Minas Gerais, 1999. 360 p.

ROSCOE, R.; MERCANTE, F. M.; SALTON, J. C. Dinâmica da matéria Orgânica do solo em sistemas conservacionistas. Dourados: Embrapa Agropecuária Oeste, 2006. 304 p.

SALOMÃO, F. X. de T. Controle e prevenção dos processos erosivos. In: GUERRA, A. J. T.; SILVA, A. S.; BOTELHO, R. G. M. (Org.). Erosão e conservação dos solos: Conceitos, temas e aplicações. 3. ed. Rio de Janeiro: Bertrand Brasil, 2007. cap. 7, p. 229-268.

SANTOS, G. G.; SILVEIRA, P. M.; MARCHÃO, R. L.; PETTER, F. A.; BECQUER, T. Atributos químicos e estabilidade de agregados sob diferentes culturas de cobertura em Latossolo do cerrado. Revista Brasileira de Engenharia Agrícola e Ambiental, Campina Grande, v. 16, n. 11, p. 1171-1178, 2012.

SEKI, A. S. et al. Efeitos de práticas de descompactação do solo em área sob sistema plantio direto. Revista ciência agronômica, Fortaleza, v. 46, n. 3, p. 460-468, jul. 2015. Disponível em: < http://www.redalyc.org/html/1953/195338412002/>. Acesso em: 25 set. 2017.

SOUSA, D. M. G.; MIRANDA, L. N.; OLIVEIRA, S. A. Acidez do solo e sua correção. In: NOVAIS, F. R.; ALVARES, V. V. H.; BARROS, N. F.; FONTES, R. L.; CANTARUTTI, R. B.; NEVES, J. C. L. (Ed.). Fertilidade do solo. Viçosa, 2007, p. 210. 
TEDESCO, M. J.; GIANELLO, C.; BIASANI, A. A. Análise de solo, plantas e outros materiais. 2. ed. Porto Alegre: Departamento de Solos da Faculdade de Agronomia da UFRGS, 1995.

Recebido em: 13/03/2016 Aceito em: 24/05/2018 